\title{
Evaluasi Resiliensi Pasien Penyalahguna Narkotika Di Balai Besar Rehabilitasi Badan Narkotika Nasional
}

\author{
Dipa Tri Adhitya*, Palupi Lindiasari Samputra \\ Program Kajian Ketahanan Nasional, Universitas Indonesia \\ *Correspondence email: dipatri.dta@gmail.com
}

\begin{abstract}
Abstrak. Peraturan BNN RI Nomor 24 tahun 2017 tentang Pelayanan Rehabilitasi Bagi Pecandu Dan Korban Penyalahguna Narkotika memiliki kewenangan dalam melakukan rehabilitasi bagi penyalahguna narkotika. Rehabilitasi membantu memulihkan pecandu dari kecanduannya akan narkotika. Dengan Resiliensi yang baik maka pasien akan mampu untuk pulih atau menyesuaikan diri dari kemalangan. Tujuan dari penelitian ini untuk menganalisis faktor yang menentukan tingkat resiliensi dan menganalisis indeks resiliensi pasien penyalahguna narkotika dalam menjalani rehabilitasi di Balai Besar Rehabilitasi BNN. Penelitian ini menggunakan metode kuantitatif jenis survey dengan sampel responden sebanyak 140. Metode analisis data menggunakan analisis faktor dan indeks tingkat resiliensi. Hasil penelitian menunjukan terdapat lima faktor resiliensi dari pecandu, yaitu Kontrol Impuls, Empati, Regulasi Emosi, Pencapaian dan Analisis Masalah. Kelima faktor ini dapat menjelaskan pengaruhnya terhadap resiliensi sebesar 63,079\%. Pecandu menunjukan tingkat resiliensi yang tinggi 82,33\% setelah mengikuti program rehabilitasi.
\end{abstract}

Kata Kunci: Resiliensi; rehabilitasi penyalahguna

Abstract. BNN RI Regulation Number 24 of 2017 concerning Rehabilitation Services for Addicts and Victims of Narcotics Abuse has the authority to carry out rehabilitation for narcotics users. Rehabilitation helps the addict recover from his addiction to drugs. With good resilience, the patient will be able to recover or adjust to adversity. This study aimed to analyze the factors that determine the level of strength and analyze the resilience index of narcotic abusers undergoing rehabilitation at the BNN Rehabilitation Center. This study used a quantitative method of survey type with a sample of 140 respondents. The data analysis method used factor analysis and index of resilience level. The results showed five factors of the resilience of addicts, namely Impulse Control, Empathy, Emotion Regulation, Achievement, and Problem Analysis. These five factors can explain the effect on the strength of $63.079 \%$. Addicts show a high level of resilience of $82.33 \%$ after following a rehabilitation program

Keyword: Resillience; rehabilitation of narcotics abusers

\section{PENDAHULUAN}

Pemerintah melalui UU Narkotika No 35 tahun 2009, Pasal 54 bertujuan untuk melakukan upaya pencegahan, perlindungan dan penyelamatan penyalahguna dari kecanduan melalui program rehabilitasi. Selanjutnya BNN mengimplementasikan Undang-undang tersebut melalui peraturan No 24 Tahun 2017 tentang Layanan Rehabilitasi Bagi Pecandu Dan Korban Penyalahgunaan narkotika. Peraturan ini menjadi dasar bagi Badan Narkotika Nasional untuk memiliki kewenangan dalam melakukan rehabilitasi bagi penyalahguna narkotika. Penyalahguna narkotika berdasarkan Undang-undang Narkotika no 35 tahun 2009 pada pasal 1 ayat (15) adalah orang yang menggunakan narkotika tanpa hak atau melawan hukum. Tahapan penyalahgunaan narkotika menurut US National Comission On Marijuana and Drugs Abuse diklasifikasikan menjadi lima tahap, yaitu: Experimental User, Recreational User, Situasional Users, Intensified Users, Compulsive Dependence Users.

Penanganan penyalahguna yang tidak tepat akan berdampak pada kekambuhan (relapse) oleh penyalahguna sehingga diperlukan penanganan yang tepat dan komprehensif. Aspek rehabilitasi dalam Undang-undang narkotika merupakan aspek utama dalam memberantas masalah penyalahgunaan dan peredaran gelap narkotika, karena penyalahguna ditinjau dari sudut kesehatan adalah orang sakit adiksi narkotika kronis; penyalahguna ditinjau dari sudut hukum adalah pelaku tindak pidana yang hanya bisa tobat, tidak mengulangi perbuatannya apabila dihukum dengan hukuman rehabilitasi (Iskandar, 2020). Oleh karenanya rehabilitasi menjadi solusi dalam menangani penyalahguna narkotika dibandingkan dengan penjara. Penyalahguna kalau dijatuhi sanksi penjara justru menimbulkan residivisme dan meningkanya jumlah penyalahgunaan dan peredaran gelap narkotika (Iskandar, 2020). Sehingga penanganan penyalahguna narkotika dengan rehabilitasi diharapkan mampu mengatasi kecanduan dari pengguna narkotika karena didalam rehabilitasi penyalahguna diatasi masalah kesehatan baik fisik maupun psikis sehingga dapat menciptakan mantan penyalahguna yang resilien (Iskandar, 2019).

Rehabilitasi narkotika adalah suatu cara yang dimiliki tempat rehabilitasi yang memberikan pelatihan suatu keterampilan dan pengetahuan bagi penyalahguna narkotika agar berhenti menggunakan kecanduannya akan narkotika. Dan tahapan rehabilitasi dalam Undangundang RI No 35 Tahun 2009 terdapat dua (2) jenis 
rehabilitasi, diantaranya: Rehabilitasi Medis dan Rehabilitasi Sosial.

Rehabilitasi yang dilakukan oleh BNN diharapkan dapat mengurangi prevalensi hingga ke tahap penyembuhan bagi pecandu. Salah satu indicator yang dapat dijadikan acuan dari keberhasilan program, rehabilitasi adalah seberapa besar tingkat ketahanan atau resiliensi pecandu dalam memproteksi dirinya untuk tidak menggunakan narkotika Kembali. Resiliensi merupakan kemampuan individu dalam mengatasi tantangan dalam kehidupannya serta kemampuan seseorang untuk berusaha agar tidak mudah menyerah, selanjutnya mampu kembali bangkit serta mampu merubah menjadi pribadi yang lebih baik dari yang sebelumnya, (Mufidah, 2017). Sedangkan (Aisha, 2014) dalam jurnalnya mengatakan, menghentikan penggunaan NAPZA bisa dikatakan sulit, namun terdapat salah satu cara yaitu dengan meningkatkan resiliensi.

Dari survey awal peneliti di Balai Besar Rehabilitasi BNN didapatkan rasio relapse sebagai berikut:

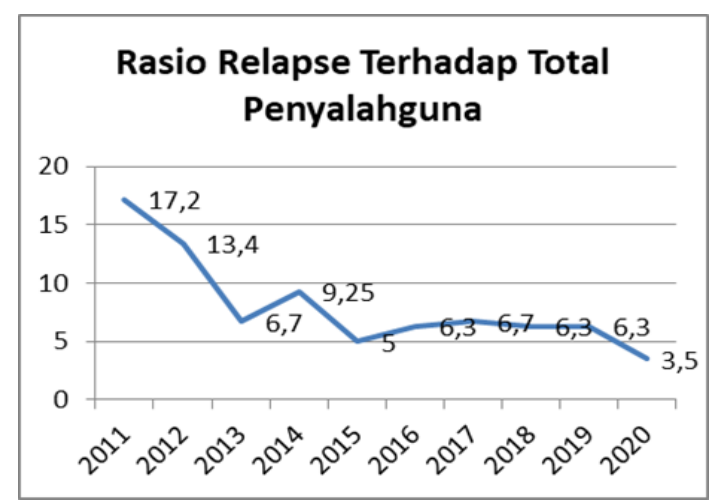

Gambar 1. Rasio Relapse terhadap Total Penyalahguna Sumber: Data Balai Besar Rehabilitasi BNN

Melihat data itu, tren relapse pada tahun 20112013 mengalami penurunan. Namun, pada tahun 20152019 , penyalah guna yang relapse mengalami kenaikan (Nova, 2019). Dan pada tahun 2020 terjadi penurunan jumlah penyalahguna narkotika di Balai Besar Rehabilitasi BNN dikarenakan terjadinya pandemic covid 19 dan Balai Besar Rehabilitasi BNN memberlakukan kebijakan kawasan terbatas sehingga membatasi kedatangan pasien penyalahguna narkotika untuk mencegah terjadinya penularan Covid 19.

Penurunan rasio relapse merupakan indikasi keberhasilan program rehabilitasi. Namun, karena terdapat faktor eksternal seperti adanya pandemic-19 penilaian ini tidak cukup kuat hanya dari melihat laju penurunan relapse saja. Dibutuhkan ukuran lain yang dapat dijadikan acuan dalam penilaian tingkat efektifitas program rehabilitasi BNN bagi para pecandu. Dalam penelitian ini menggunakan pendekatan tingkat reseliensi pecandu.

Penelitian tentang resiliensi pernah dilakukan oleh (Suryaman dkk, 2013). Penelitian dilakukan di Yayasan
Rumah Damai dengan menggunakan analisis regresi. Hasil penelitian menemukan bahwa resiliensi pada pasien rehabilitasi narkoba berpengaruh dalam memudahkan pasien sembuh. Resiliensi yang tinggi dapat membantu pasien terhindar dari jeratan narkoba sehingga dapat terlindungi dari efek negative yaitu relapse.

Penelitian lainnya dilakukan oleh (Aisha, 2014), yang menjelaskan hubungan antara Religiuitas dengan Resiliensi pada Remaja Di Panti Asuhan Keluarga Yatim Muhammadiyah Surakarta. Peneliti menggunakan sampel 50 responden, dan terdapat hubungan positif yang sangat signifikan antara religiuitas dengan resiliensi. Serta tingkat resiliensi yang tergolong tinggi. Religiuitas menjadikan individu mampu bertahan, bangkit dan menyesuaikan dengan kondisi sulit selama tingaal di panti asuhan. Selanjutnya resiliensi yang dimiliki individu dapat mempengaruhi kesuksesannya dalam melakukan adaptasi didalam keadaan yang penuh stressor. (Satria, 2016) melakukan penelitian ini dengan menggunakan 30 responden. Hasilnya didapatkan 56,7\% resiliensi pasien rehabilitasi NAPZA.

Berdasarkan latar belakang masalah diatas, maka penelitian ini bertujuan untuk menganalisis faktor yang menentukan tingkat resiliensi dan menganalisis indeks resiliensi pasien penyalahguna narkotika dalam menjalani rehabilitasi di Balai Besar Rehabilitasi BNN.

State Of The Art. Dalam penelitian ini yang terbaru adalah peneliti menambahkan perspektif dari ketahanan nasional terhadap resiliensi penyalahguna narkotika, dan menggunakan kuisioner resiliensi yang sudah dimodifikasi sehingga sesuai untuk mendapatkan data resiliensi pasien di rehabilitasi narkotika. Penelitian ini menggunakan pengukuran resiliensi dengan menggunakan rumus (Dixon \& Massey, 1991) sehingga akan didapatkan indeks dari resiliensi pasien penyalahguna narkotika di Balai Besar Rehabilitasi BNN. Dalam penelitian ini lebih rinci menggunakan analisis faktor explanatory secara statistic terkait faktorfaktor yang mempengaruhi resiliensi pasien penyalahguna narkotika berbeda dengan penelitian terdahulu yang kebanyakan hanya menampilkan skala resiliensi pada penyalahguna narkotika saja.

\section{Literature Review}

Terdapat dua landasan teori yang digunakan dalam penelitian ini, yaitu teori analisis kebijakan khususnya pada tahap analisis evaluasi, dan konsep resiliensi. (William, 2003) menjelaskan arti dari evaluasi merupakan suatu usaha yang dilakukan dengan cara seperti penaksiran, pemberian angka dan penilaian dari suatu kebijakan yang telah dilakukan dalam bentuk nilai atau kata-kata. Dalam arti yang lain, evaluasi berkenaan terhadap hasil dari suatu produk kebijakan berupa informasi atau manfaat dari hasil kebijakan. Hal ini menerangkan bahwa evaluasi kebijakan merupakan hasil 
dari kebijakan yang mempunyai nilai dari tujuan atau sasaran kebijakan, dimana bagian akhir dari suatu proses kebijakan adalah evaluasi kebijakan. Kriteria Evaluasi diantaranya ; efisiensi, kecukupan, pemerataan, Resposnsivitas, dan ketepatan.

Konsep resiliensi secara etiomologis menurut (Masten \& Gerwitz, 2006) arti resiliensi dari segi bahasa mempunyai makna suatu kapasitas untuk kembali pulih atau bangkit kembali. Berdasarkan (American Psikological Association, 2017), resiliensi merupakan suatu proses beradaptasi dengan cukup baik menghadapi kesulitan, trauma, ancaman, atau sumber stress. Dalam hal ini menjadi seseorang yang resilen tidak berarti seseorang tidak mengalami kesulitan dalam kehidupannya. Pasti memiliki luka seperti perasaan dan kesedihan seperti halnya dirasakan oleh seseorang yang mengalami hambatan dan trauma di dalam hidupnya. Seseorang seringkali mendapat tekanan perasaan emosi disaat akan menjadi seseorang yang resilien. Bahwasannya orang resilien juga tidak semata-mata terbebas dari tekanan yang mampu memberikan sesuatu yang menimbulkan trauma dalam kehidupannya. Sedangkan menurut (Utami dan Hemil, 2017) resiliensi juga menjelaskan bahwa individu memiliki kemampuan dalam menyelesaikan suatu masalah yang datang dan mengatasi kesulitan tersebut dalam setiap kehidupannya.

Perbedaan penelitian ini dari penelitian sebelumnya terletak pada studi kasus yang digunakan adalah pasien pecandu yang mendapat rehabilitasi di BNN, serta pengukuran indeks resiliensi untuk mengukur seberapa besar tingkat ketahanan pasien untuk tidak relapse (kambuh).

Menurut (Usman. Wan, 2018) dalam bukunya Konsep Ketahanan Nasional dapat didefinisikan sebagai kondisi dinamis suatu bangsa yang meliputi semua aspek kehidupan untuk tetap jaya ditengah keteraturan dan perubahan yang selalu ada. Kondisi ini tersirat bahwa ketahanan nasional dapa berupa kondisi dinamis suatu bangsa serta dapat pula metode untuk mencapai tujuan agar suatu bangsa tetap jaya. Sedangkan dalam pandangan LEMHANAS dalam bukunya (Usman. Wan, 2018) merupakan kondisi dinamis bangsa Indonesia yang berisi keuletan dan ketangguhan dalam menghadapi dan mengatasi segala ancaman, gangguan, hambatan dan tantangan (AGHT) baik dari luar maupun dari dalam negeri, langsung atau tidak langsung yang dapat membahayakan integritas, identitas serta kelangsungan hidup bangsa dan negara.

\section{METODE}

Penelitian ini akan menggunakan metode kuantitatif jenis survey. Lokasi penelitian di Balai Besar Rehabilitasi BNN. Data bersifat primer dan dikumpulkan dengan kuesioner. Responden penelitian ini adalah pasien yang sedang menjalani rehabilitasi di Balai Besar Rehabilitrasi BNN.
Variabel Dependen yaitu resiliensi, merupakan kemampuan untuk bertahan dari suatu masalah yang dihadapi dan dialami oleh pasien. Pasien yang resilien akan lebih mudah bertahan dalam menhadapi suatu tekanan atau stressor sehingga gangguan emosi dan gangguan perilaku yang timbul akan lebih sedikit sehingga akan lebih mudah dalam menjalani rehabilitasi dan pulih. Sedangkan variabel Independen terdiri dari tujuh aspek resiliensi yaitu: regulasi emosi yaitu cara individu mengidentifikasi stimulus yang diterima dan meresponnya secara positif maupun negatif, kontrol impuls adalah pengendalian emosi dan respon individu terhadap stimulus sehingga individu mampu merespon stimulus tersebut dengan keaadaan dalam diri individu tersebut, optimism yaitu kepercayaan individu terhadap kemampuannya dalam menyelesaikan suatu masalah yang dihadapi, analisis kausal merupakan kemampuan individu dalam mengidentifikasi penyebab dari masalah yang dihadapinya sehingga individu tersebut mampu menyelesaikan masalah yang dialaminya, empati adalah suatu kemampuan yang dimiliki dalam memahami dan merespon keadaan/ perasaan orang lain, efikasi diri merupakan kepercayaan diri dalam menghadapi dan menyelesaikan masalah yang dialami secara komitmen, dan sedangkan pencapaian merupakan keberaniaan individu dalam menjalani kehidupan dengan penuh tanggung jawab serta menghadapi tantangan kehidupan yang baru, (Reivich dan Shatte, 2002). Berdasarkan teori Slovin, jumlah sampel responden yang digunakan adalah 153 orang. Pengambilan sampel dengan teknik random sampling.

Rumus Slovin:

$n=\frac{N}{1+N(e)^{2}}$

Ket: Populasi $=160$ orang dan e $=5 \%$

Kriteria inklusi sampel: Residen yang sudah dalam fase program rehabilitasi, Residen male dan female, Usia $\geq 15$ tahun

Kriteria eksklusi sampel: Gangguan jiwa berat dan Tidak bisa baca dan tulis

Analisis data memiliki beberapa tahapan, yang pertama melakukan uji validitas dan reliabilitas terhadap pertanyaan-pertanyaan yang digunakan dalam kuesioner. Selanjutnya, dilakukan analisis faktor untuk menentukan faktor-faktor resiliensi. Kemudian tahap terakhir menghitung indeks resiliensi pasien. Berdasarkan menurut (Dixon \& Massey, 1991) perhitungan indeks dapat menggunakan rumus CSI, lalu nilai indeks dimasukkan dalam kriteria di indeks berikut:

$$
\text { CSI }=\frac{\sum_{i=1}^{p} W S i}{5} x 100 \%
$$


Dipa Tri Adhitya dan Palupi Lindiasari Samputra, Evaluasi Resiliensi Pasien Penyalahguna Narkotika Di Balai Besar Rehabilitasi Badan Narkotika Nasional

\begin{tabular}{ccc}
\hline No & Nilai Indeks & Kriteria \\
\hline 1. & $80 \%-100 \%$ & Resilien Sangat Tinggi \\
2. & $60 \%-79 \%$ & Resilien Tinggi \\
3. & $40 \%-59 \%$ & Cukup Resilien \\
4. & $20 \%-39 \%$ & Kurang Resilien \\
5. & $0 \%-19 \%$ & Tidak Resilien \\
\hline
\end{tabular}

\section{HASIL DAN PEMBAHASAN}

Sebelum dilakukan analisis faktor, peneliti melakukan uji validitas dan reliabilitas terhadap pertanyaan-pertanyaan dalam kuesioner. Terdapat 56 pertanyaan yang diujikan dari 7 aspek yang menentukan resiliensi. Hasil uji tersebut terlihat pada Tabel 1.

Tabel 1. Uji Reliabilitas

\begin{tabular}{|c|c|}
\hline Reliability Statistics \\
\hline Cronbach's Alpha & N of Items \\
\hline .850 & 56 \\
\hline
\end{tabular}

Sumber: data diolah (2020)

Nilai Uji Cronbach's Alpha yang diinginkan adalah > 0,7. Dan terlihat pada Table 1 nilai yang didapatkan adalah 0,850 sehingga kuesioner memenuhi syarat reliabilitas. Sedangkan dari hasil validasi dari 56 pernyataan kuesioner didapatkan 14 item yang dapat dikatakan valid dengan nilai P-value > r-tabel 0,283. Dengan range antara $0,492-0,886$.

Selanjutnya untuk menguji apakah variablevariabel yang digunakan dapat di analisis dengan analisis faktor, maka perlu dilakukan uji KMO dan Bartlett's. Nilai tersebut menunjukkan seberapa faktorfaktor tersebut mampu menjelaskan pengaruh terhadap resiliensi. Nilai KMO yang diharapkan adalah lebih besar dari 0,5. Hasil analisis memperlihatkan nilai KMO sebesar 0,732 dimana >0,5. Sementara itu, signifikansi yang dihasilkan yaitu sebesar 0,000 atau lebih kecil dari 0,05 . Dengan hasil tersebut, maka variabel dan sampel penelitian memungkinkan untuk dilakukan analisis lebih lanjut.

Tabel 2. Uji KMO dan Bartlet's KMO and Bartlett's Test

\begin{tabular}{|c|c|c|}
\hline \multicolumn{2}{|c|}{$\begin{array}{l}\text { Kaiser Meyer Olkin Measure Of Sampling } \\
\text { Adequacy }\end{array}$} & 0,732 \\
\hline \multirow{3}{*}{$\begin{array}{l}\text { Barltets Test Of } \\
\text { Sphericity }\end{array}$} & Approx Chi Square & 469,423 \\
\hline & df & 91 \\
\hline & Sig & 0,000 \\
\hline
\end{tabular}

Sumber: output SPSS 2020

Terdapat Component berjumlah 14 yang merupakan jumlah item indicator variabel independen. Dengan demikian, karena nila Eigen yang ditetapkan adalah lebih dari 1, maka terdapat 5 (lima) faktor yang terbentuk dalam penelitian ini. Variabel penelitian ini dapat dijelaskan oleh faktor 1 hingga faktor 5 artinya, resiliensi dapat menjelaskan variabel independen sebesar 63,079\% terhadap variabel dependen, pada Tabel 3 .
Tabel 3. Total Variance Explained

\begin{tabular}{|c|r|r|r|}
\hline \multirow{2}{*}{ Component } & \multicolumn{3}{|c|}{ Initial Eigenvalues } \\
\cline { 2 - 4 } & Total & \% of Variance & Cumulative \% \\
\hline 1 & 3,876 & 27,684 & 27,684 \\
\hline 2 & 1,419 & 10,134 & 37,817 \\
\hline 3 & 1,287 & 9,190 & 47,007 \\
\hline 4 & 1,186 & 8,473 & 55,480 \\
\hline 5 & 1,064 & 7,599 & 63,079 \\
\hline 6 & 0,909 & 6,493 & 69,572 \\
\hline 7 & 0,778 & 5,560 & 75,132 \\
\hline 8 & 0,682 & 4,870 & 80,002 \\
\hline 9 & 0,646 & 4,614 & 84,616 \\
\hline 10 & 0,626 & 4,472 & 89,088 \\
\hline 11 & 0,490 & 3,498 & 92,586 \\
\hline 12 & 0,430 & 3,072 & 95,658 \\
\hline 13 & 0,411 & 2,934 & 98,591 \\
\hline 14 & 0,197 & 1,409 & 100,000 \\
\hline
\end{tabular}

Sumber: output SPSS 2020

Terdapat 14 Component berjumlah 14 yang merupakan item indicator variabel independen. Dengan demikian, karena nilai Eigen yang ditetapkan adalah lebih dari 1 , maka terdapat 5 faktor yang terbentuk dalam penelitian ini. Variabel penelitian ini dapat dijelaskan oleh faktor 1 adalah $3,876 / 14 \times 100 \%=$ 27,684 persen, faktor $21,419 / 14 \times 100 \%=10,134$ persen, faktor $31,287 / 14 \times 100 \%=9,190$ persen, faktor 4 $1,186 / 14 \times 100 \%=8,473$ persen dan faktor $51,064 / 14 \times$ $100 \%=7,599$ persen. Artinya, kelima faktor ini dapat menjelaskan sebesar $27,684 \%+10,134 \%+9,190 \%+$ $8,473 \%+7,599 \%=63,079 \%$ terhadap resiliensi.

Selanjutnya untuk menentukan item pernyataan masuk kedalam suatu faktor dapat dilihat dalam table rotated component matrices. Penentuan tersebut untuk menentukan masing-masing indicator akan masuk ke dalam faktor 1,2,3,4 atau 5. Penentuan input item indicator ke faktro tertentu tergantung pada besarnya korelasi antara variabel dengan faktor.

Berdasarkan cara tersebut, didapatkan pengelompokkan faktor dan variabel anggotanya sebagai berikut: Komponen 1 diisi oleh item dari Kontrol Impuls, Komponen 2 diisi item dari Empati, Komponen 3 diisi item Regulasi Emosi, Komponen 4 diisi item dari Pencapaian dan komponen 5 diisi item dari Analisis Masalah.

Tabel 4. Perhitungan Indeks Resiliensi

\begin{tabular}{lccc}
\hline \multicolumn{1}{c}{ Faktor } & $\begin{array}{c}\text { Loading } \\
\text { Faktor }\end{array}$ & Bobot & Indeks Item \\
\hline Regulasi Emosi & 1,206 & 12,217 & 49,321 \\
Kontrol Impuls & 1,382 & 14,000 & 55,830 \\
Empati & 1,583 & 16,046 & 61,217 \\
Optimis & 1,403 & 14,213 & 63,238 \\
Analisis Masalah & 1,580 & 16,005 & 65,002 \\
Efikasi Diri & 1,180 & 11,953 & 53,567 \\
Pencapaian & 1,536 & 15,57 & 63,503 \\
\multicolumn{4}{c}{ Total Indeks } \\
\end{tabular}

Sumber: diolah 2020 
Dari hasil perhitungan penilaian tingkat resiliensi dengan cara menghitung indeks tingkat resiliensi, cara ini bertujuan untuk mengetahui tingkat resiliensi pasien penyalahguna selama di rehabilitasi hasilnya $82,335 \%$ yaitu sangat tinggi.

Hal ini sejalan menurut (UNODC, 2016) bahwa Pendampingan intensif dan suportif yang diterima pasien dalam perawatan rehabilitasi dengan kegiatan terstruktur dan aturan program rehabilitasi akan membantu pasien mengembangkan Kontrol Impuls yang lebih baik dan menunda kepuasan saat belajar keterampilan untuk mengatasi frustasi dan mengatasi stress. Serta adanya komitmen konkrit akan membantu mengembangkan kemampuan pribadi dan mengevaluasi kemajuan pribadi dengan pencapaian yang terukur. Kontrol impuls juga terkait dengan regulasi emosi dengan ini jika kontrol impuls kuat maka akan diikuti dengan regulasi emosi yang kuat pula, sebaliknya jika dengan kontrol impuls yang rendah akan cepat mengalami suatu perubahan emosi. Pasien dalam menjalani rehabilitasi sudah pasti akan mengikuti treatment yang ada dalam proses rehabilitasi sehingga pasien akan berlatih dan mampu dalam mengendalikan emosi dalam diri pasien.

Empati memberikan pengaruh kedua yang mana sejalan dengan penelitian dari (Maesaroh dkk, 2019) bahwa salah satu faktor yang berpengaruh positif signifikan terhdap resiliensi yaitu salah satunya empati yang merupakan faktor protektif internal individu. Resiliensi akan lebih baik jika mengoptimalkan empati dan self awareness. Ketidakmampuan pasien dalam empati dapat berdampak pada kesuksesan dan menunjukkan perilaku tidak resilien, karena pasien tidak mampu mengerti petunjuk dari orang lain terkait kondisi emosional pasien tersebut yaitu berkaitan denga hubungan dengan orang lain/ pasien lain dalam rehabilitasi. Dengan empati yang baik akan memperkuat hubungan sosial yang positif antar pasien.

Penyalahguna narkotika cenderung beralih dari masalah dengan menggunakan narkotikanya, dalam menyelesesaikan masalah membutuhkan kemampuan menganalisa masalah dan optimis sehingga masalah yang dimiliki seorang penyalahguna dapat diselesaikan. Hal tersebut sejalan dengan teori yang dikemukakam (Grotberg, 1995) menunjukkan individu atau seseorang bisa menyelesaikan tantangan dari suatu masalahnya adalah individu/ seseorang yang bisa melakukan penilaian terhadap suatu masalah yang dialaminya secara alami, serta mengerti akan suatu hal yang menjadi kebutuhan untuk menyelesaikan masalah dan bantuan apa yang dibutuhkan dari orang lain untuk menyelesaikan masalah tersebut.

Diterangkan kembali oleh (Grotberg, 1999) yaitu suatu kemampuan seseorang/individu dalam menyelesaikan masalah yang dibutuhkan untuk membangun resiliensi individu, karena dengan kemampuan serta kepercayaaan dalam menyelesaikan masalah tersebut sangat dibutuhkan, guna menghadapi masalah yang ada.

Penelitian yang dilakukan (Listyanti, 2012), adanya hubungan yang positif dan signifikan antara regulasi emosi dengan resiliensi, jadi semakin tinggi suatu regualasi emosi individu maka akan semakin tinggi pula resiliensinya, begitu sebaliknya. Kemampuan dalam mengatur emosi dan menempatkan emosinya dalam kondisi yang tepat maka akan meningkatkan hubungan interpersonal pasien karena dalam proses rehabilitasi hubungan interpersonal sangat perperan penting dalam pembentukan resiliensi pasien dalam menjalani rehabilitasinya.

Seseorang dengan kontrol impuls yang tinggi maka akan mempunyai regulasi emosi yang tinggi juga. Namun ketika seseorang tidak memiliki kemampuan dalam mengontrol impuls, maka individu akan menerima belief/ keyakinan yang pertama kali datang pada dirinya dan tanpa mempertimbangkan hal-hal lainnya. Sehingga berakibat individu tersebut cenderung lebih percaya terhadap suatu kejadian negative dan belief atau keyakinannya juga akan mengikuti. Sehingga individu yang mempunyai kontrol impuls dapat menahan dan mengevaluasi suatu hal kejadian negative yang menimpanya dan mampu berfikir rasional.

Pencapaian merupakan gambaran individu dalam mencapai suatu keberhasilan. Sehingga pasien dengan resiliensi yang tinggi maka akan mengembalikan tujuan hidup pasien. Dengan pencapaian dalam diri pasien penyalahguna narkotika akan mengembalikan suatu tantangan dalam menemukan hal yang positif dan pembelajaran baru dalam hidup pasien.

Dalam proses rehabilitasi sebagai suatu kebijakan dalam solusi menangani permasalahan penyalahguna narkotika, maka dapat dikatakan memberikan konstruksi positif terhadap resiliensi. Resiliensi pasien penyalahguna narkotika selama menjalani rehabilitasi di Balai Besar Rehabilitasi BNN didapatkan hasil yang sangat tinggi dengan hasil perhitungan indeks $82,335 \%$. Hal ini dikarenakan rehabilitasi dengan lingkungan yang sudah dibentuk oleh lembaga BNN dengan staff-stafnya yang komitmen dalam memberikan layanan professional dapat dikatakan efektif dalam memngkontruksi resiliensi pasien.

Kebijakan rehabilitasi dapat menjadi solusi yang lebih baik bagi penyalahguna narkotika dibandingkan penyalahguna narkotika masuk penjara. Sehingga dapat mencegah terjadinya residivis pecandu dan hal ini akan menjadi suatu ancaman ketahanan nasional dikarenakan permintaan akan narkotika selalu akan ada jika penyalahguna tidak menghentikan kecanduannya. Hal ini telah sesuai dengan konvensi tunggal narkotika 1961 dengan diamandemenkan protocol 1971 bahwa penyalahguna yang semula diberikan sanksi pidana penjara diganti menjadi sanksi alternative berupa sanksi rehabilitasi. (Iskandar, 2020) 
Dipa Tri Adhitya dan Palupi Lindiasari Samputra, Evaluasi Resiliensi Pasien Penyalahguna Narkotika Di Balai Besar Rehabilitasi Badan Narkotika Nasional

\section{SIMPULAN}

Penelitian ini menghasilkan temuan bahwa terdapat 5 faktor yang mempengaruhi resiliensi yaitu Kontrol Impuls, Empati, Regulasi Emosi, Pencapaian dan Analisis Masalah, dengan total memberikan gambaran 63,079\%. Tingkat resiliensi pasien penyalahguna selama di rehabilitasi di Balai Besar Rehabilitasi BNN hasilnya 82,33\% yaitu sangat tinggi. Kebijakan terkait pengaturan rehabilitasi efektif dalam memberikan konstruksi resiliensi pasien penyalahguna narkotika di Balai Besar Rehabilitasi BNN. Diperlukan adanya penelitian selanjutnya dalam melihat faktor eksternal seperti adanya peraturan Protokol Kesehatan di masa Pandemic Covid-19 yang mempengaruhi resiliensi.

\section{DAFTAR PUSTAKA}

Aisha, D. L. (2014). Hubungan antara spiritualitas dengan resiliensi pada remaja di panti asuhan keluarga yatim muhammadiyah Surakarta.Universitas Muhammadiyah Surakarta: Fakultas Psikologi.

Amacon. Reivich, K., \& Shatte, A. (2002). The Resilience Factor: 7 Keys To Finding Your Inner Strength And Overcome Life's Hurdles. New York: Broadway Books.

APA (American Psychological Association). (2017). Stress in America ${ }^{\mathrm{TM}}$ 2017: Technology and Social Media. Part 2. Stresinamerica.org

Dixon, W \& Massey, J. 1991. Pengantar Analisis Statistik, Yogyakarta: Gajah Mada Press

Dunn, William N. 2003. Pengantar Analisis Kebijakan Publik ed.2. Gajah Mada University Press

Grotberg, Edith H. 1995. A Guide to Promoting Resilience in Children: Strengthening the Human Spirit. Den Haag; Bernard Van Leer Foundation.

Grotberg, Edith H. 1999.Tapping Your Inner Strengh: How to Find the Resilience to Deal with Anything. Oakland, CA: New Harbinger Publications, Inc

Iskandar, Anang. 2019. Penegakan Hukum Narkotika (Rehabilitatif Terhadap Penyalah Guna Dan Pecandu, Represif Terhadap Pengedar). Kompas Gramedia. Jakarta

Iskandar, Anang. 2020. Politik Hukum Narkotika. Kompas Gramedia. Jakarta

Listyanti Widuri, Erlina. 2012. Regulasi Emosi Dan Resiliensi Pada Mahasiswa Tahun Pertama. Jurnal Humanitas.

Maesaroh, Siti dkk. 2019. Ancaman, Faktor Protektif, Dan Resiliensi Remaja Di Kota Bogor.Jurnal Ilmu Keluarga dan Konseling. IPB

Masten \& Gerwirtz. 2006. Resilience in Developmen: The Importance of Early Chilhood. Encyclopedia on Early Chilhood Development I Center of Excellence for Early Chilhood Development Masten AS. University of Minnesota, USA.

Mufidah, A.C. 2017. Hubungan antara dukungan sosial dengan resiliensi yang dimoderatori oleh locus of control pada mahasiswa bidikmisi. Jurnal Psikodimensia

Nova I., Regina. 2019.Pengaruh Perilaku Merokok Pada Penyalah Guna Narkotika Terhadap

Kecenderungan Relapse Di Balai Besar Rehabilitasi Lido. Jakarta

Satria, Budi. 2016. Resilience Of Drug Patient During Mental Rehabilitation. Idea Nursing Journal

Suryaman, A., S, dan Sugiarta., Mabruri, I. (2013).Pengaruh Spiritualitas Terhadap Resiliensi Pada Pasien Rehabilitasi Narkoba Yayasan Rumah Damai Semarang . Universitas Negeri Semarang : Psikologi dikutip dari http://journal.unnes.ac.id/sju/index.php/dcp 2.

UNODC. 2016. Standar Internasional untuk Rawatan Gangguan Penyalahgunaan Napza.WHO.

Usman. Wan. 2018. Buku Bunga Rampai Ketahanan Nasional. Sekolah Ketahanan Stratejik dan Global. Universitas Indonesia. Jakarta

Utami, C.T. \& Helmi, A.F. 2017. Self Efficacy dan Resiliensi: Sebuah Tinjauan Meta-Analisis. Buletin Psikologi Vol 25. UGM Yogyakarta.

UU No 35 tahun 2009 tentang narkotika 